\title{
ESCUELA COLOMBIANA DE REHABILITACIÓN
}

La Escuela Colombiana de Rehabilitación inició labores académicas como Escuela Nacional de Fisioterapia, el $1^{\circ}$ de Abril de 1952, reconocida y aprobada por el Decreto No. 1 del Consejo Directivo de la Escuela Superior de Higiene y como entidad adjunta al Instituto Franklin Delano Roosevelt.

En 1960 cambian su nombre por el de Fundación Colombiana de Rehabilitación quedando constituida dicha fundación el 16 de Julio de 1963.

El Ministerio de Justicia, le concede personería Jurídica mediante Resolución No. 3381 de Julio de 1964 publicada por el Diario Oficial No. 31455 de Septiembre de 1964.

En el 1966 se crea la Escuela Colombiana de Fonoaudiología aprobada por el Ministerio de Educación Nacional por resolución No. 2183 del 18 de Marzo de 1977.

La idea de conformar la Carrera de Terapia Ocupacional, fue concebida por la Junta Administradora de la Fundación Colombiana de Rehabilitación a comienzos de la década de los sesenta, con el fin de dar una respuesta de prestación de servicios a población afectada física y psíquicamente, buscando la integración de estos individuos como personas útiles a la sociedad. Esta idea empezó a cristalizarse con la capacitación y formación de recurso humano en diferentes programas de Terapia Ocupacional tanto en el país como fuera de él.

En el año de 1969, se da inicio a la Carrera de Terapia Ocupacional bajo el apoyo y respaldo académico del Colegio Mayor de Nuestra Señora del Rosario y de la Fundación Colombiana de Rehabilitación, presidida por el Doctor Juan Ruiz Mora, mediante convenio celebrado un año antes y con la coordinación de la Terapeuta Ocupacional Claudia Uribe de Piedrahita, Fisioterapeuta de la Escuela Colombiana de Rehabilitación y Terapeuta Ocupacional de la Universidad Nacional.

En sus inicios, el programa se dirigió a la enseñanza de una amplia gama 
Se dio, así una apertura en la prestación de servicios, al tomar al individuo dentro del medio ambiente humano y no humano, favoreciendo el enten, dimiento pleno del término «adaptación» como factor fundamental de nuestra acción profesional.

Otro de los avances importantes de resaltar, fue el cambio operado en los programas de práctica docente asistencial vigentes en el momento, al incluirse en cada uno de ellos actividades correspondientes a los tres niveles de atención primaria, secundaria y terciaria, factor que facilitó nuestra acción como profesional capacitados para el manejo integral de individuo y no solamente como rehabilitadores en el sentido textual de la palabra.

Con base en esta apertura se permitió ampliar y profundizar la aplicación de la rehabilitación profesional como área importante y que respondía en ese momento a los programas de prestación de servicios de Terapia Ocupacional, con el fin de buscar en el individuo desde la atención primaria, el desarrollo de destrezas y habilidades que facilitaran su ubicación laboral, logrando la Facultad un reconocimiento por el desempeño de sus profesionales en esta área a nivel Nacional e Internacional.

En el área investigativa se buscó dar al educando una mayor cantidad de elementos y herramientas permitiendo el desarrollo de actividades y proyectos que generarán, sustentarán o adaptarán conocimientos propios de Terapia Ocupacional a partir del manejo de técnicas de investigación y análisis de información.

En el año de 1986 se eleva a la categoría de Facultad la Carrera de Terapia Ocupacional, hecho que plantea nuevas orientaciones y tendencias hacia el desarrollo y promoción, de actividades que consolidan el verdadero espíritu universitario.

La evolución histórica de la disciplina ha llevado a que al interior de las facultades que forman recurso humano en el área generarán el análisis y reestructuración de sus currículos buscando una identidad profesional y un objeto de estudio que les sean propios fortaleciendo el rol del Terapeuta Ocupacional en una sociedad cambiante y dinámica y acorde a la realidad social, cultural, laboral, educativa y de salud entre otros del país; como parte de nuestra responsabilidad para convertirlo en objeto de conocimiento y sugerir hipótesis de solución que pueden insertarse luego en 
los planes de desarrollo que atienden las exigencias del crecimiento humano y del bienestar general, ya que como cita la ley diez (10) de reestructuración de la educación «la supervivencia y el bienestar de la especie, es en último término, la finalidad del conocimiento y la producción de éste tiene en la universidad su lugar natural».

Es así como entre 1988 y 1990 se plantea una reestructuración del plan de estudios cuyo objetivo fundamental es ajustar la estructura curricular a las necesidades que la formación requiere para un adecuado desempeño del profesional acorde con el perfil profesional y planteándose como áreas del conocimiento la psicobiológica, ocupacional, investigativa, administrativa y la social humanística.

Se define por ese período la Filosofía con énfasis en una visión humanística, pero se evidenciaba que pese a estos esfuerzos del ejercicio profesional predominaba el modelo médico. En consecuencia se realizó una propuesta de cambio curricular buscando el giro de dicha filosofía, reforzando el área investigativa y la orientación humanística con el objetivo de formar profesionales independientes, así mismo se ampliaron los campos de intervención del sector salud a la educación regular, a la industria y a la consulta privada, permitiendo la actualización y la proyección de la disciplina con énfasis en la relación del profesional con su medio.

Finalmente en 1992, se planteó la última reestructuración del plan de estudios con el fin de que la formación del estudiante de pregrado estuviera acorde con las políticas de un país en desarrollo y con las necesidades de la comunidad a la cual brinda sus servicios. Por lo tanto, se instituyeron asignaturas que ampliaran la visión social, en el área de metodología de la investigación se incluyó la base epistemológica. El área de Humanidades se reestructuró con base en los aspectos éticos, situación social y económica en América Latina, con especial énfasis en la situación colombiana y en la misión rosarista y de la Escuela Colombiana de Rehabilitación afiliada al Colegio Mayor de Nuestra Señora del Rosario.

Actualmente los campos de acción incluyen la tradicional área de salud ampliada a la prevención y a la promoción de la salud en la comunidad. En el área educativa, se incrementaron los procesos, estudia la perspectiva de salud ocupacional. En los últimos tres años se extendió la participación del Terapeuta Ocupacional en el sector justicia a nivel de rehabilita- 
ción carcelaria.

A partir de Noviembre de 1994 la Escuela Colombiana de Rehabilitación asume una identidad propia con orgullo para conformar la Institución Universitaria Escuela Colombiana de Rehabilitación con las Facultades de Fisioterapia, Fonoaudiología y Terapia Ocupacional, continuando con una excelencia académica en la formación de profesionales que respondan a las necesidades del país.

La última reforma curricular en 1996, está orientada por los principios humanistas articulados con las modificaciones y revoluciones en el ámbito social, cultural, económico y político, con las tendencias de la Comunidad Internacional de Terapia Ocupacional y con las necesidades del país.

En este delineamiento se pretende alcanzar una flexibilidad curricular siendo por tanto el plan de estudios, el comienzo de un proceso más amplio de reforma y de renovación de modelos, enfoques y prácticas tendientes a lograr una formación integral, desarrollando competencias respecto a la observación, pensamiento crítico, solución de problemas e intervención ocupacional.

Los ejes conceptuales del plan curricular, están dados por la filosofía de la ECR, la ley 30 , la concepción de Universidad y educando y los ejes centrales de la ocupación Humana en lo concerniente al comportamiento ocupacional, ocupación, actividades de la vida diaria, roles y hábitos, mirando la perspectiva de hombre, del mundo, de la ciencia, de formación. de universidad.

El plan de estudios refleja tanto la misión de la institución como de Terapia Ocupacional, los objetivos educacionales del programa, las competencias a ser logradas, la organización de las asignaturas, la selección de contenidos, secuencia de trabajo, con miras a sustentar un ejercicio profesional con un eje epistemológico y teórico referido a la Ocupación Humana y un orden metodológico e histórico para posibilitar una relación dinámica tanto del docente como del estudiante en la identificación, delimitación y análisis de problemas y paradigmas de Terapia Ocupacional, para generar una competencia intra e interdisciplinar así como una competencia investigativa y administrativa. (Ver Diagrama Anexo) 


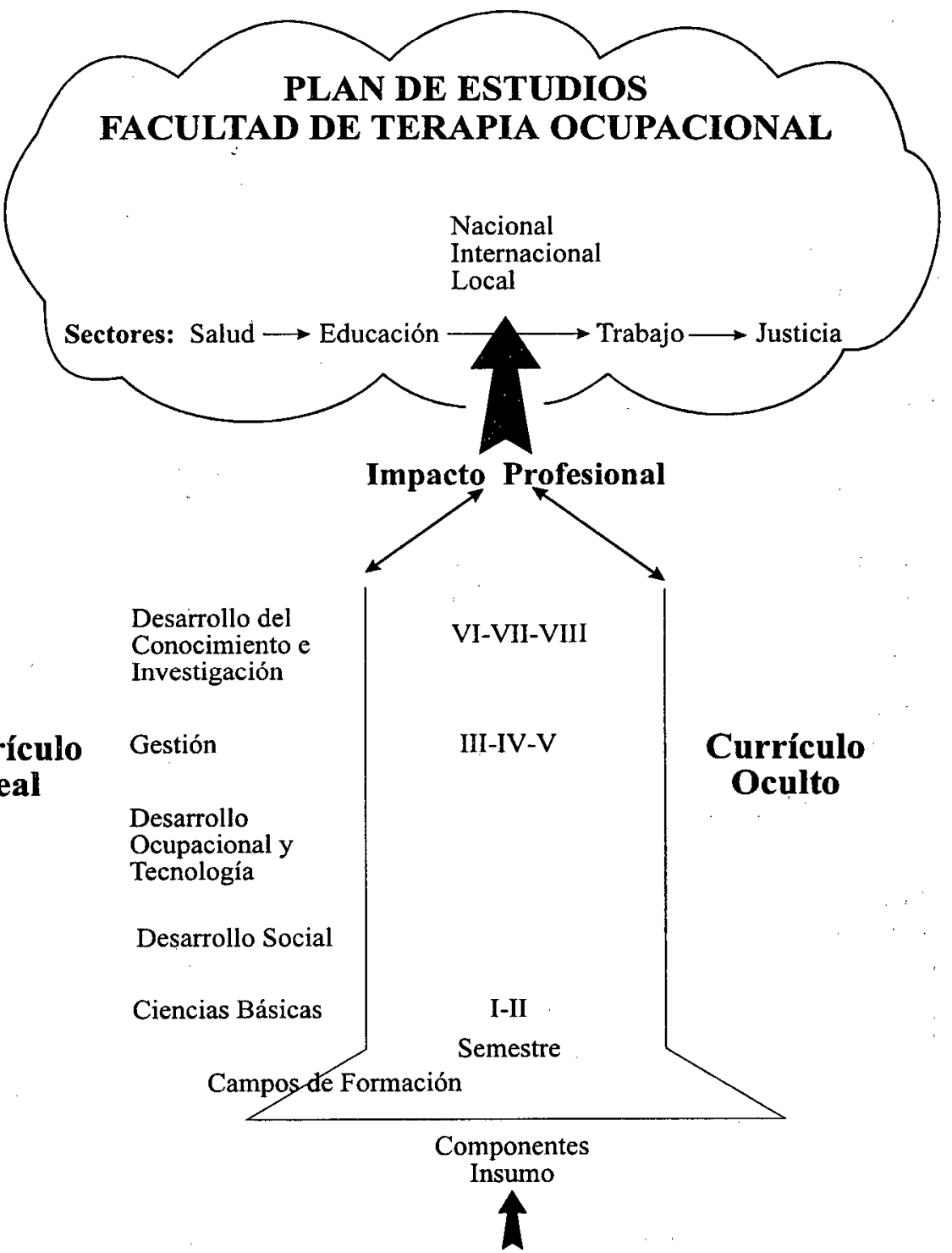

El plan de estudios está diseñado para 8 semestres de formación con los siguientes objetivos:

- Desarrollar en el estudiante habilidades y conocimientos para intervenir en la solución de problemáticas sociales en áreas de competencia de Terapia Ocupacional. 
- Facilitar el desarrollo de habilidades de liderazgo del estudiante en el abordaje e intervención en procesos sociales y ocupacionales.

- Promover en el educando habilidades para trabajar en equipo, con calidad académica y habilidades comunicativas.

- Involucrar al estudiante con las prioridades del país y las necesidades de la población en lo relacionado con comportamientos ocupacionales.

- Fortalecer la autonomía, creatividad e iniciativa en el abordaje y solución de situaciones y problemáticas individuales y colectivas.

\section{Perfil del Egresado:}

Profesional que se interesa por brindar una alta calidad en la prestación y administración de servicios, por preocuparse que sus acciones trasciendan al desarrollo de la institución prestadora de servicios tanto clínicos como educativos.

Así mismo, con su liderazgo, se ha convertido en agente integrador de la comunicación interdisciplinaria favoreciendo el trabajo en equipo. Como mecanismo centralizador de las acciones profesionales en pro del bienestar ocupacional de los sujetos de intervención.

También a través de su proceso de intervención, nuestro profesional es apto para el conocimiento e interpretación de conductas ocupacionales estando en la capacidad de responder a necesidades personales y colectivas para alcanzar mejores niveles de competencia personal y social, como por ejemplo la promoción del comportamiento ocupacional, la prevención de un desequilibrio en el mismo y la rehabilitación física, sensorial o mental.

Por tal motivo, está en capacidad de asumir retos de carácter investigativo en sus áreas de desempeño, con el propósito de cualificar, trascender y dar sentido a sus propios límites de conocimiento que le permita incursionar en otros campos de acción a nivel político, estratégico y operativo, lo que lo hace un profesional importante en dar respuestas a las situaciones sociopolíticas del país. 


\section{PRÁCTICAS DE CAMPO}

Se considera que las prácticas de campo son una exposición progresiva y secuenciada del estudiante al ejercicio profesional desde el primer semestre a través del manejo de eventos prácticos que en coordinación con los contenidos teóricos, se introducen teniendo en cuenta un orden ascendente de exigencia, existiendo 3 niveles:

\section{Nivel I}

\section{Prácticas de Complementación Académica:}

Aplicación de: primero à quinto semestre

El estudiante asume un rol de observador con el fin de confirmar, complementar y reforzar contenidos teóricos a través de las diferentes asignaturas, para desarrollar habilidades y destrezas mínimas básicas para su quehacer profesional.

\section{Nivel II}

\section{Prácticas de campo:}

Aplicación: sexto a octavo semestre

La práctica institucional se constituye en una estrategia de trabajo en equipo en la cual participa la comunidad, las instituciones prestadoras de servicios y formadoras de recurso humano, cuyo fin primordial es el ajuste permanente del conjunto que conforma la oferta de servicios a las necesidades de la demanda.

La base de las prácticas institucionales es la necesidad de enfrentar al estudiante con la realidad para consolidar los conocimientos y verificar sus habilidades y destrezas en el desempeño como Terapeuta Ocupacional.

Dicho nivel comprende 3 etapas evolutivas: de iniciación, sustentación y monitoría.

\section{Nivel III}

\section{Práctica de Extensión}

Aplicación: séptimo y octavo semestre

Se desarrolla sobre campos por el impacto social o por el aporte científico, se constituyen en áreas de interés para la facultad. 


\section{EDUCACIÓN POSTGRADUAL}

La Facultad de Terapia Ocupacional de la Escuela Colombiana de Rehabilitación ha ido implementando procesos de educación continuada en forma permanente hasta generar en el presente año el inicio de un Diplomado en Férulas.

Igualmente inició la primera cohorte de la Especialización en Ergonomía y continúa sus estudios para implementar nuevas propuestas de especialización en el sector educativo y tecnológico.

\section{EGRESADOS DE LA FACULTAD:}

La Facultad de Terapia Ocupacional ha egresado un total de 465 Terapeutas Ocupacionales desde 1974 a 1996, con la afiliación del Colegio Mayor de Nuestra Señora del Rosario. En el presente año, sacará la primera promoción como Institución Universitaria independiente. 